\title{
TIMBER SHEATHED WALLS FOR WIND AND EARTHQUAKE RESISTANCE
}

\author{
D. J. Dowrick1 and P. C. Smith2
}

\begin{abstract}
This paper discusses the principles of timber sheathed walls (shear walls), gives guidance on modelling, analysis and details, and reviews the relevant research on behaviour under cyclic loading. The scope of the paper is limited to walls sheathed with plywood, particle or fibre board sheets, nailed to the framing. With appropriate nailing details, good performance under wind and earthquake loads can be obtained.
\end{abstract}

\begin{abstract}
1. INTRODUCTION
This paper is one of a series of papers on the design of timber structures for wind and earthquake resistance, resulting from the work of a joint committee of the New Zealand Timber Design Society and the New Zealand National Society for Earthquake engineering (Williams, 1986). This paper discusses the behaviour and design of timber sheathed walls which will perform well in both wind and earthquake loading. The dominant consideration is the achievement of ductile behaviour without excessive loss of strength under strong seismic excitation.

With the latter in mind the present discussion is Iimited to those forms of construction which currently promise the best toughness under strong earthquake loads as follows:
\end{abstract}

Sheathing materials

- plywood

- particle board (medium and high density only)

- fibre board

Method of fixing sheathing to framing

\section{- nails}

It is noted that while sheathing in the traditional form of boarding (ie narrow strips) may be satisfactory it will not be discussed here. Also we note that design provisions for gluing as an alternative to nailed fixing will not be discussed here, although it may be included in the committee's reports later in the light of the work of Yap (1985).

This paper is concerned with ductile walls only, which mostly occur as simple cantilevers, but coupled pairs of walls may also be used. As yet no cyclic

$1_{\text {physics and Engineering Laboratory, }}$ DSIR, Lower Hutt

${ }^{2}$ Spencer Holmes Miller and Partners Ltd, wellington load testing has been done on the latter form of timber shear wall, but theoretical design procedures for what are in effect walls with large openings are available (Dean et al, 1984).

As all of the cyclic load tests so far carried out have been on cantilever walls, the content of this paper generally is based on them. We recommend that highly stressed ductile timber cantilever sheathed walls should not be penetrated by large openings, and sheathed walls which are highly stressed under earthquake loads should preferably have none but the smallest of openings. As timber itself fails in a brittle manner, at least in tension, the ductility of sheathed walls has to be produced by ensuring that either the nails or the holding down bolts at the base yield rather than failure occurring in the timber, ie a capacity design approach is required.

Nail yielding is ensured by using nails of the appropriate number, type and proportion as discussed in separate companion papers in this series (Collins, 1986 and Dean et al, 1986). Undesirable non-ductile failure modes that have to be prevented by providing sufficient load capacity typically include the following:

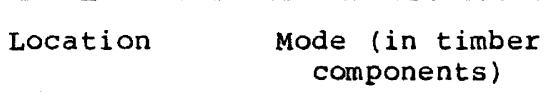

Panel

interior

Rolling shear - (Glued construction) Shear

Buckling

\begin{tabular}{ll}
$\begin{array}{c}\text { Edge fixing } \\
\text { (panel to } \\
\text { framing) }\end{array}$ & $\begin{array}{l}\text { Tearing of panel } \\
\text { Nail withdrawal } \\
\text { (premature) } \\
\text { Nail rotation (rigid body) }\end{array}$ \\
\hline $\begin{array}{l}\text { Boundary } \\
\text { (at base) }\end{array}$ & $\begin{array}{l}\text { Shear } \\
\text { Tension (overturning) } \\
\text { Compression (overturning) }\end{array}$
\end{tabular}


Finally it is noted that the good performance of sheathed walls under loading depends strongly on good detailing, so that careful attention to nailing parameters such as edge distance and spacing is essential. The abovementioned nail yield design procedure provides a ductility level that is implied in the SM factors that have been under study for deriving the earthquake design loads for the New Zealand code NZS 4203, as described in the companion papers of Dean et al (1986) and Moss et al (1986). Good performance under seismic loading will also depend on control of horizontal deflection which may govern the design of more slender walls.

2. RESEARCH INTO LATERAL LOAD RES ISTANCE OF TIMBER SHEAR WALLS

This brief review refers to the main research work of interest to this paper, namely plywood and particle board sheathings, and the resistance of such walls to lateral loading particularly of a cyclic nature.

The original work on the resistance of timber shear walls to cyclic loading was that done over 20 years ago by Medearis (1962, 1966). Investigating plywood sheathed walls, he obtained good hysteretic behaviour with high energy absorption (fat hysteresis loops) and no strength degradation in the loading range of interest. His walls were 8 ft $(2.4 \mathrm{~m})$ square with plywood thicknesses of $3 / 8,1 / 2$, and $3 / 4$ inch, nailed to redwood framing.

After Medearis there is a gap in published research on cyclic loading, until the current spate of interest in New Zealand during the last few years. The first sign of renewed interest is some unpublished cyclic load tests carried out by Brickell Moss and Partners (1978) on walls of high aspect ratio $(\mathrm{H} / \mathrm{B}=2.4)$ sheathed with medium grade particle board. These gave encouraging results and led to the Ministry of Works and Development carrying out further tests on particle board walls (Thurston and Flack, 1980). The latter tests were on squat walls $(\mathrm{H} / \mathrm{B}=1)$ and confirmed that medium grade particle board sheathing behaved in a similar manner to that found for plywood by Medearis, with high ductility and energy absorption being apparent (Fig 1).

The above work on particle board was followed by the examination of plywood sheathed walls at Canterbury University and at the Ministry of Works and Development. The former work has been conducted during the current doctoral thesis studies of $W$ G Stewart and is therefore not yet fully documented. However it has included cyclic load tests of different types of holding down connections (Stewart et al, $1984)$ and cyclic load tests of squat shear walls $(\mathrm{H} / \mathrm{B}=1)$, which comprised both static cycling and shake-table

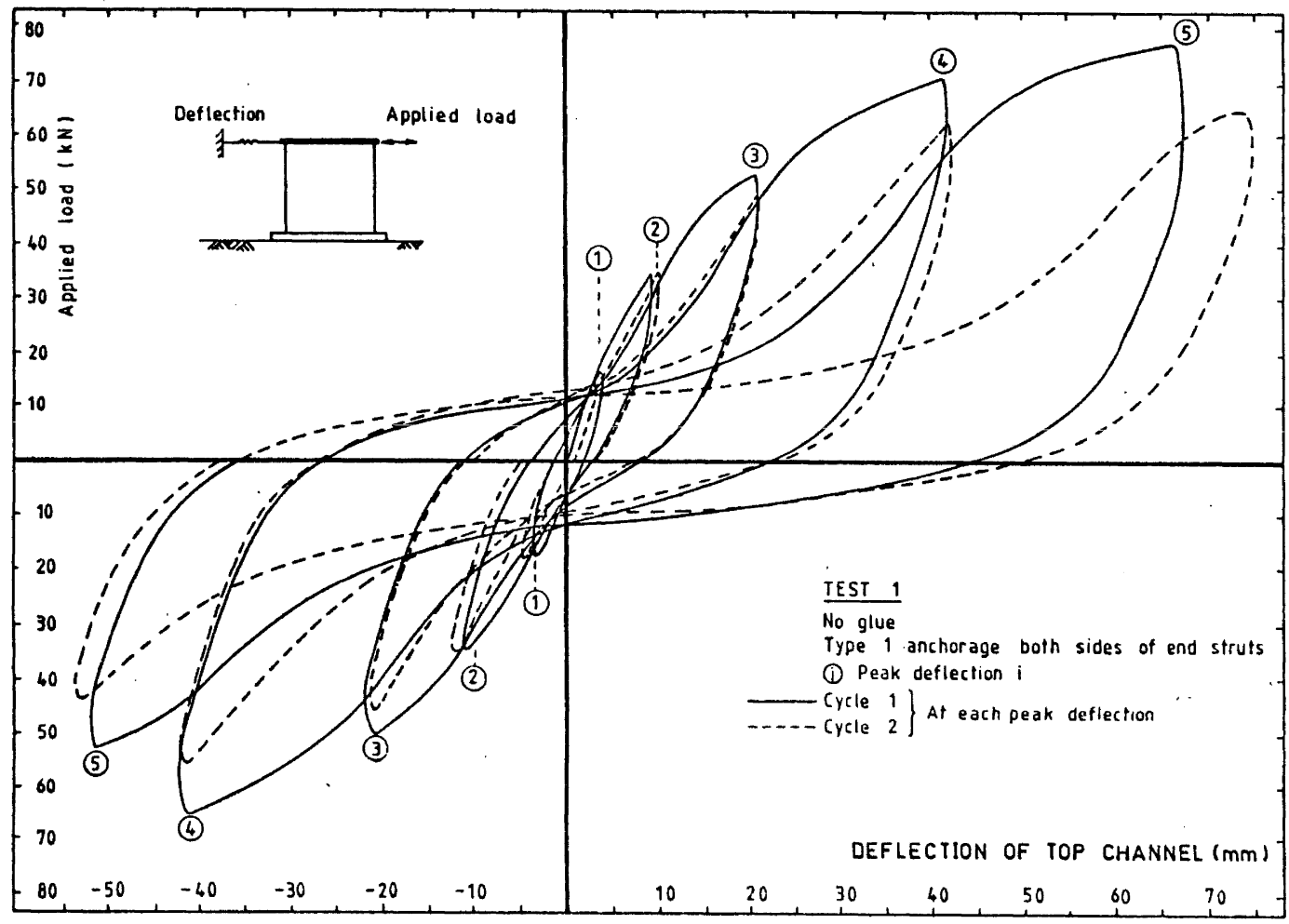

Fig 1. CYCLIC LOAD TEST ON PARTICLE BOARD SHEATHED WALL (FROM THURSTON AND FLACK, 1980) 


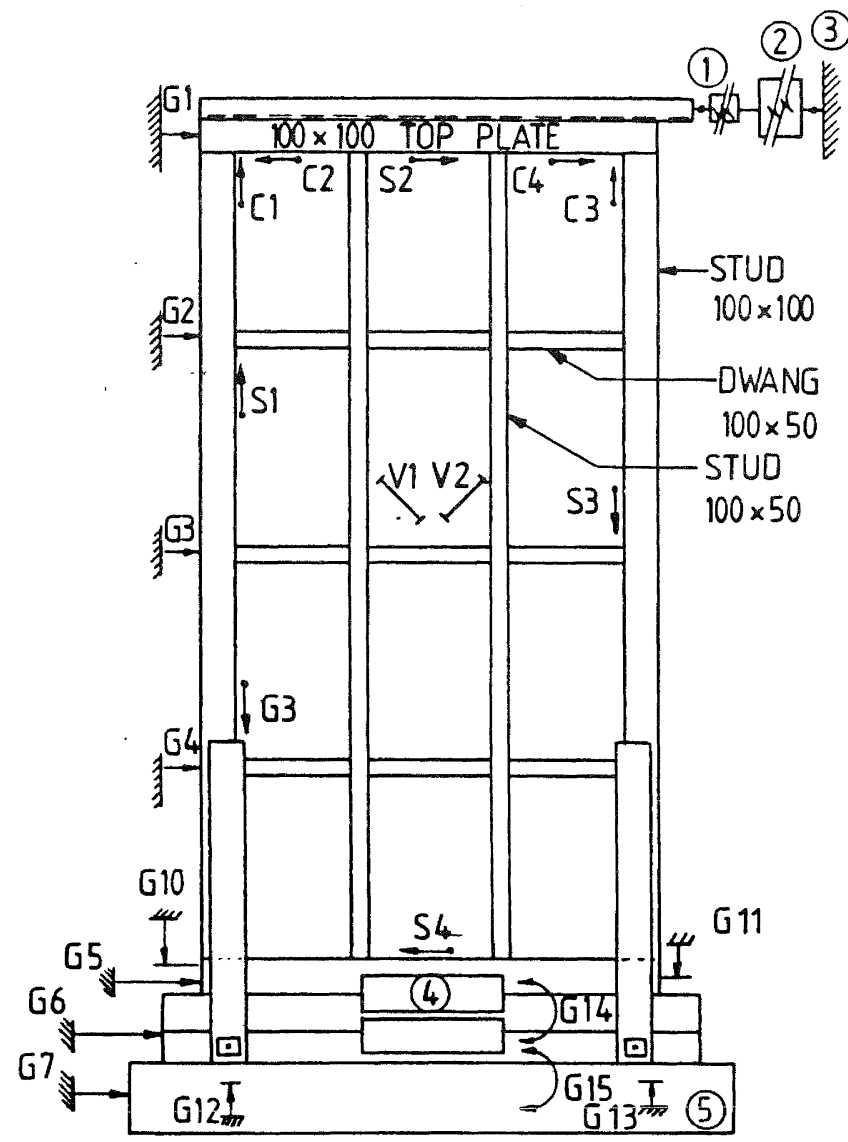

Fig 2. TEST SET.UP FOR CYCLIC LOAD TEST RESULTS SHOWN IN FIG 3 (FROM THURSTON, 1984) dynamic tests. This research is contributing strongly to our understanding of appropriate equivalentstatic code design loads (ie SM factors) and the final outcome of this work is awaited with interest.

The Ministry of Works and Development research on behaviour of plywood sheathed walls under cyclic loading (Thurston and Hutchison, 1984; Thurston, 1984) involved tests on walls of two different aspect ratios, $H / B=2$ and $2 / 3$, all walls being $2.4 \mathrm{~m} \mathrm{high}$. The hysteretic behaviour of a wall with $\mathrm{H} / \mathrm{B}=2(\mathrm{Fig} \mathrm{2})$ is shown in $\mathrm{Fig} 3$ and is typical of all test results.

The singular characteristic feature of the behaviour of plywood and particle board walls is the progressive pinching of hysteresis loops under repeated cycles of loading. Fortunately. although the stiffness degrades in the initial displacement range of each cycle, the strength does not decay at higher displacements within the displacement range of design interest. The main objective of our committee's work has thus been to understand fully the implications of this pinched hysteretic behaviour for the acceptable seismic response of structures, and hence to develop design and detailing together with relevant code loadings which make proper use of the ductility and energy absorption potential of timber sheathed walls.

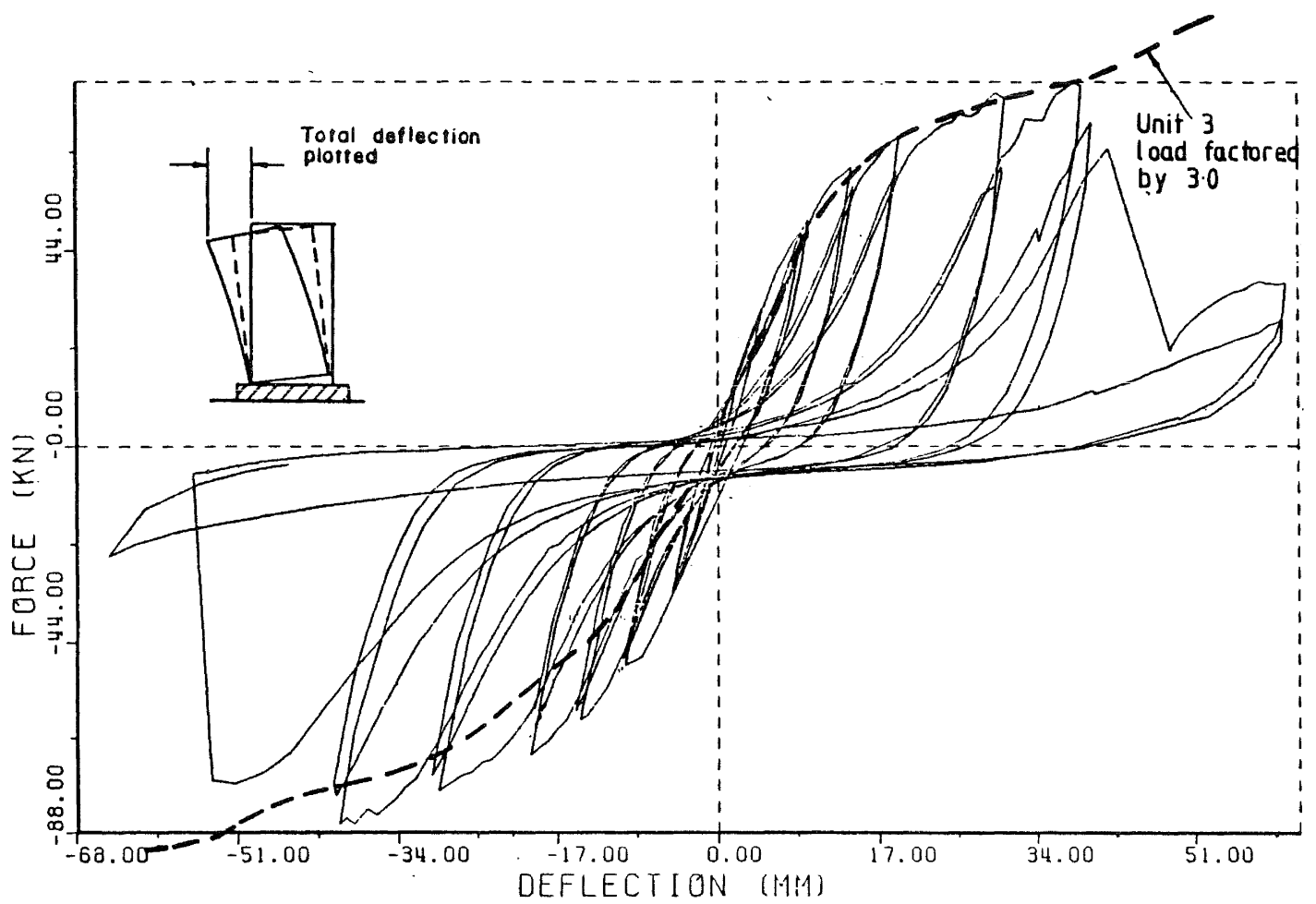

Fig 3. CYCLIC LOAD TEST ON PLYWOOD SHEATHED WALL (FROM THURSTON, 1984) 
Thurston (1984) compared the behaviour of the Ministry of Works and Development tests on plywood and particle board sheathed walls, and found them to be very similar. The close similarity of the nail slip curves for the two materials (Fig 4 a) leads to similar overall behaviour of the corresponding walls (Fig 4 b).

The influence of non-elastomeric glue on the cyclic behaviour of walls sheathed with $9 \mathrm{~mm}$ plywood has been studied by yap (1985), who found that behaviour was essentially elastic up to failure, ie behaviour was brittle. Failure was in glue bond and sheathing tension, and it was thought that failure was initiated by plywood buckling.
A review of the hysteresis behaviour of all types of timber structures has been carried out by Dowrick (1985, 1986) together with a review of computer modelling techniques. This was used as a basis for studies establishing code loadings structural factors (SM factors) reported elsewhere in this series of papers (Dean et al, 1986; Moss et a1, 1986).

\section{APPORTIONING LOADS}

The gravity and lateral loads on each wall unit should be determined using a rational method of analysis.

The distribution of lateral loads is determined by the flexibility of the

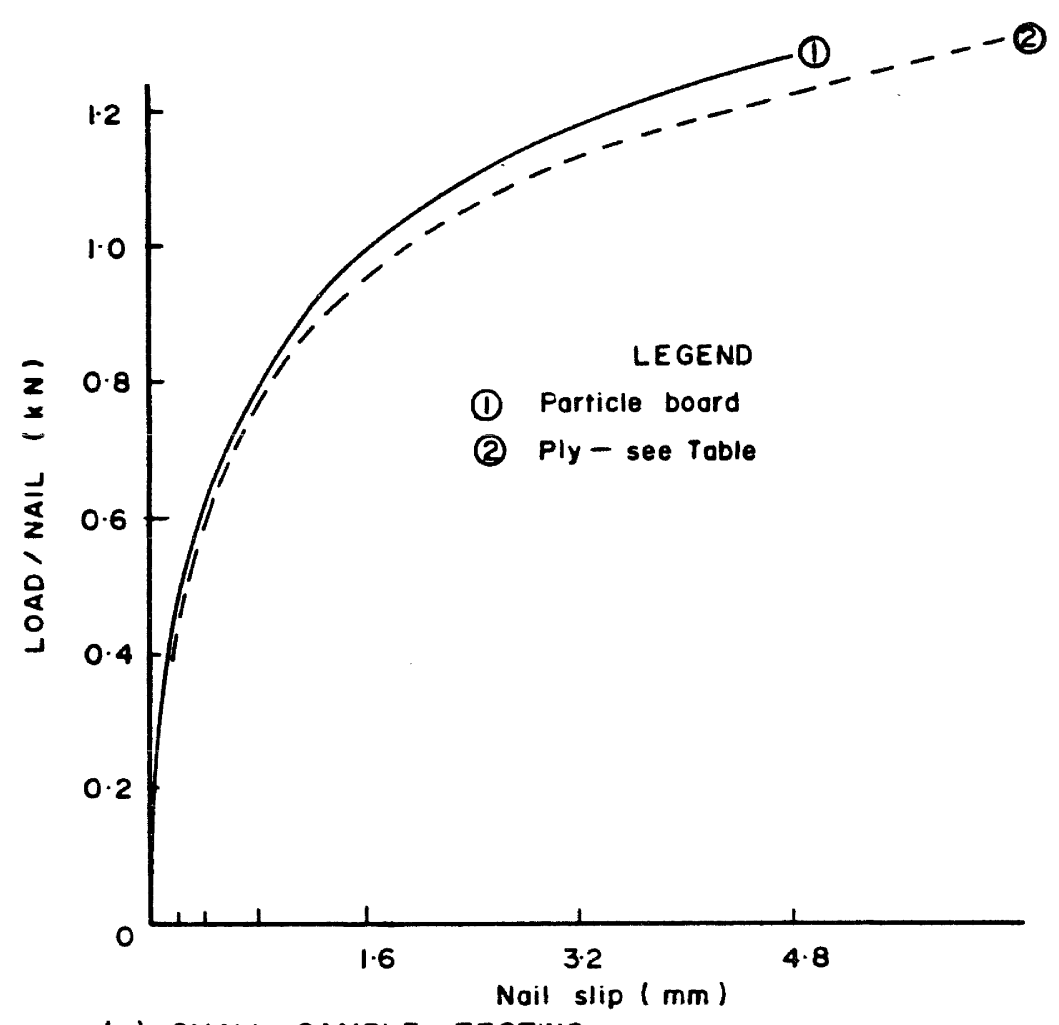

(a) SMALL SAMPLE TESTING

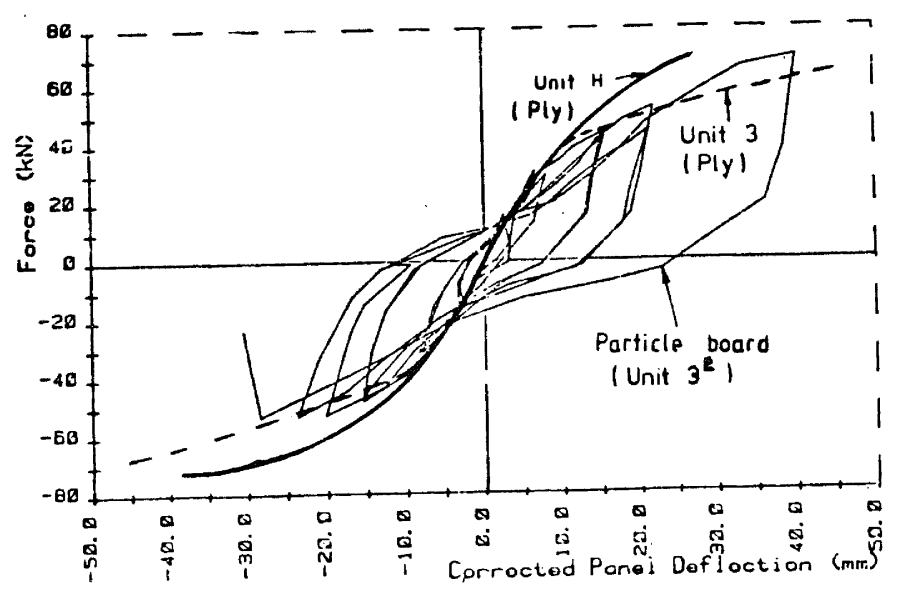

Fig 4. COMPARISON OF NAIL SLIP AND PANEL DEFLECTION FOR PLYWOOD AND PARTICLE BOARD CLADDING (FROM THURSTON, 1984). 
diaphragm relative to the flexibility of the lateral load resisting system. Timber diaphragms are significantly more flexible than reinforced concrete diaphragms and rarely should the timber diaphragm be assumed to be rigid.

The lateral deformation at the top of a timber sheathed wall is the sum of the deflection resulting from nail deformation, bending, shear and the flexibility of the base fixings.

The distribution of lateral loads to the various lateral load resisting elements may be calculated using the beam-on-elastic-support analogy. This analysis is readily modelled on microcomputers using the diaphragm stiffness properties for the beam properties and the stiffness of the various lateral load resisting elements for the supports (spring modelled) (Smith and Dowrick, 1986).

The distribution of the lateral loads to lateral load resisting elements in proportion to the tributary areas should only be used for small unimportant structures or structures with single span diaphragms.

After the lateral load to be applied to each lateral load resisting element has been derived the individual shear walls have to be designed for these loads.

\section{RESISTANCE TO IN-PLANE HORI ZONTAL LOADS}

The overturning moment resulting from the application of the lateral load can either be resisted by a triangular load distribution along the base (Fig 5) or by concentrated loads at the extremes of the panel (Fig 6).

Where the overturning moment is assumed to be resisted by a triangular distribution, the fixing between the sheathing and the bottom plate is required to transfer the overturning moment in addition to the transfer of the lateral shear $V$ into the bottom plate.

The resisting of the overturning moment by a triangular distribution also introduces bending forces into the bottom plate and requires the fixing between the bottom plate and the foundation to be designed for the induced loads.

As the transfer of the overturning moment in addition to the lateral shear significantly increases the load in the fixing between the sheathing and the bottom plate, this paper will only consider the design of walls where end fixing is utilized to resist the overturning moment and the lateral shear force $V$ is resisted by adequate fixings between the bottom plate and the foundation.

Providing the boundary member $x O$ is capable of carrying the axial load

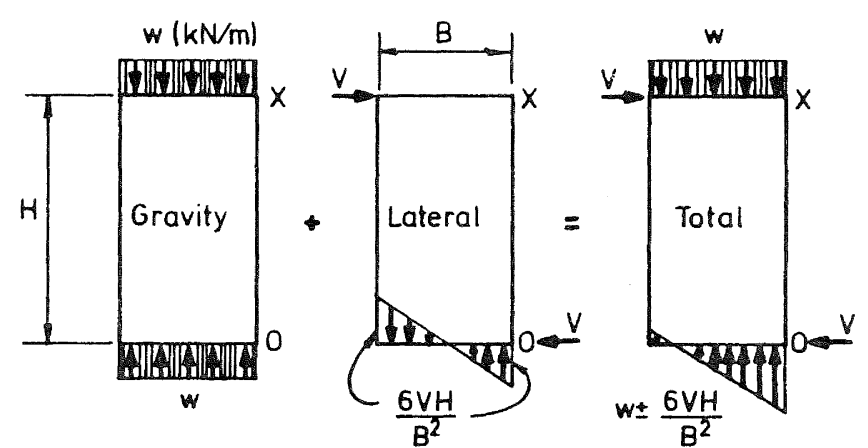

Fig 5. FORCE DIAGRAMS FOR WALLS WITH CONTINUOUS BASE RESTRAINT.

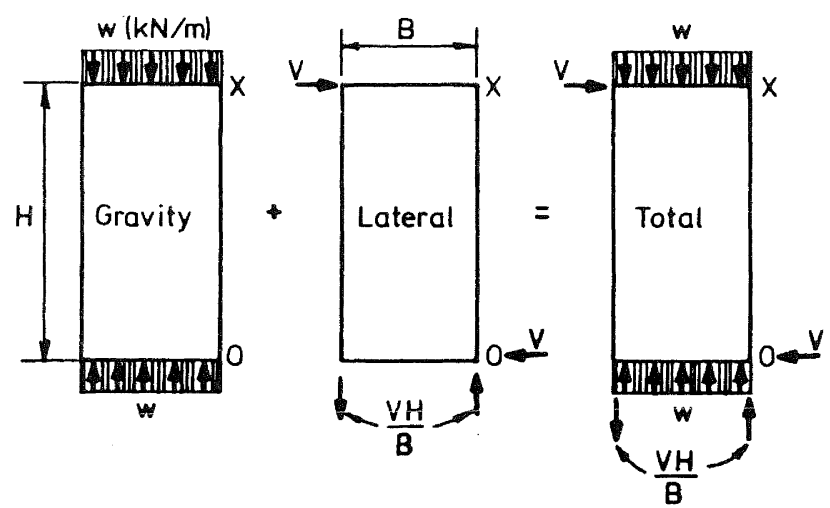

Fig 6. FORCE DIAGRAMS FOR WALLS WITH BASE FIXINGS AT ENDS ONLY.

$\mathrm{VH} / \mathrm{B}$ in compression, it is reasonable to assume that the compression force is resisted directly beneath the boundary member so that length $B$ is the horizontal distance between the centreline of the tensile connection and the centreline of the boundary member. In most walls the design lateral shear at practical nail spacings is such that the above assumption is reasonable although for heavily loaded walls the designer should check the reasonableness of this as sumption.

Where the bottom plate extends under the vertical member $x O$ it is important that the bearing pressure perpendicular to the grain is checked in the bottom plate.

\section{DESIGN OF WALL}

The design of a typical wall requires the systematic analysis of each element and the connections between all elements that constitute the completed wall assembly.

The design of wall elements should include analysis for: 
Panels

Shear stress

Panel buckling

Rolling shear

Framing Members Support of gravity loads

Resistance to axial

loads from

overturning

Secondary stresses at connections

As the wall unit achieves ductility through non-linear nail deformation or yielding of ductile base fixing details the premature failure in other than the selected failure mode must be avoided by adopting capacity design procedures for panel shear, chord design, external connections that are not load limiting etc.

The analysis of connections between elements should include the floor-wall and roof-wall connections, and connections between framing and foundations.

\section{Support of gravity loads}

Vertical gravity loads are usually considered to be distributed into the studs at the level of the top plate and to be transferred by the studs to the bottom plate without causing stress in sheathing or fastenings.

In heavily loaded walls the designer must ensure that the timber members are installed dry and constructed with bearing surfaces in contact in addition to checking the bearing strength of all connections along the load path.

\section{Resistance to axial loads from}

\section{overturning}

The overturning moment is resisted by axial loads in the boundary members at each end of the wall assembly. These loads are transferred from the sheathing into the boundary members through the nails and from the boundary members to the foundations via the base connections.

The maximum force in the boundary member occurs at the connection to the foundation and is normaliy assumed to be reaction VH/B. For ductile yielding walls subject to seismic load this reaction must be calculated using capacity design methods and all fixings sized accordingly. Appropriate allowance for reduction in thickness at connections should be included where bolts are used.

Buckling of the compressive member should be checked although for single and two storey walls it is unlikely to be critical.

\section{Design of framing}

Framing members should be designed for overstrength that occurs through development of non-linear nail deformation. All framing forces need to be increased by the ratio of nail load at the required ductility demand to the design nail load.

As well as transferring vertical loads, the nails apply reactions to the framing which must be taken into account.

These forces resolve in internal framing members and result in secondary effects in boundary framing members (Fig 7).

Further secondary effects result if base connections are not concentric and the analysis of the framing members should include such effects.

All such effects need to be considered if premature brittle failure of the framing is to be prevented.

Panel shear

The racking load causes a panel shear stress of

$\mathrm{v}=\mathrm{V} / \mathrm{Bt}$

where $v=$ racking load to individual panel $(\mathrm{kN})$

$B=$ width of sheet $(\mathrm{m})$

$t=$ thickness $(\mathrm{m})$

Again the shear $V$ must be calculated using capacity design methods when the panel is subjected to seismic loads.

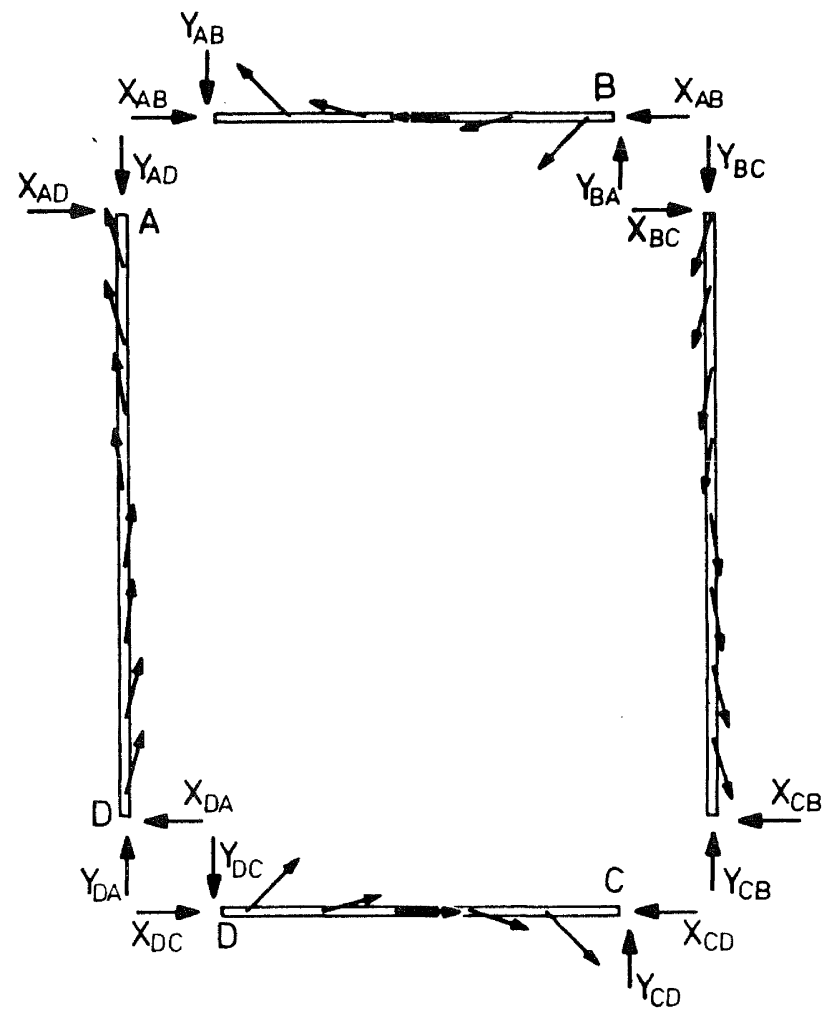

Fig 7. FORCES ON WALL FRAMING. 
Panel buckling

For thicker sheathing (eg $12 \mathrm{~mm}$ or more) the normal magnitude of racking forces which sheathing materials will be called upon to resist is unlikely to cause local buckling failure. As noted in section 2 , buckling may begin to be a problem for sheathing $9 \mathrm{~mm}$ thick. However, the thinness at which buckling may be a design problem has not been fully established. Rules for the stability of plywood panels given in NZS 3615:1981 should be interpreted in this research context.

\section{Rolling shear}

Rolling shear is that shear acting in the plane of the plies that tends to cause the wood fibres of the perpendicular plies to roll on one another. Where a plywood sheet is subjected to bending or the edges of the sheet are glued to the framing, rolling shear strength should always be calculated since the rolling shear strength of plywood is much less than the shear strength parallel to the grain.

\section{ANALYSIS OF NAIL LOADS}

After the loads and reactions on the wall panel have been established the internal forces in individual sheets of sheathing should be determined.

The resistance of a typical single sheet of cladding which is fastened to a rectangular frame is provided by the nailed connection between the sheet and the frame. While the frame tends to distort into a parallelogram shape (Fig 8a), the panel, which is essentially rigid, tends to move horizontally and to rotate under the forces imposed on it from the distortion of the frame (Fig 8b).

The relative displacement between the panel and the frame results in forces being induced in the connecting nails. walker (undated) has shown that

$$
\begin{aligned}
\frac{\theta H}{\Delta} & =\frac{\sum_{i=1}^{n} y_{i}^{2}}{\sum_{i=1}^{n}\left(x_{i}^{2}+y_{i}^{2}\right)} \\
V & =\frac{k \Delta}{H^{2}}\left(1-\frac{\theta h}{\Delta}\right) \sum_{i=1}^{n} y_{i}^{2}
\end{aligned}
$$

$F_{i}(\max )=$

$\frac{k \Delta}{2}\left(\sqrt{\left(1-\frac{\theta H}{\Delta}\right)^{2}+\left(\frac{\theta H}{\Delta}\right)^{2}\left(\frac{B}{H}\right)^{2}}\right)$

where the origin of the coordinates system is at the centre of the panel, the nailing is assumed to be symmetrical about the $x$ and $y$ axis, nail coordinates are given by $x_{i}, y_{i}$ where $i=1$ to $n$, there being $n$ ' ${ }^{\prime}$ ails around the perimeter of the cladding, and $\Delta$ and $\theta$ are as indicated in $\mathrm{Fig} 8$.

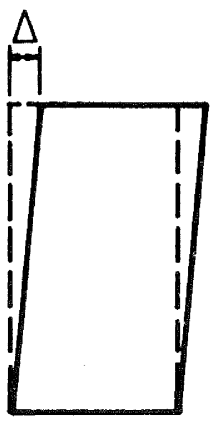

(a) Framing Deformation

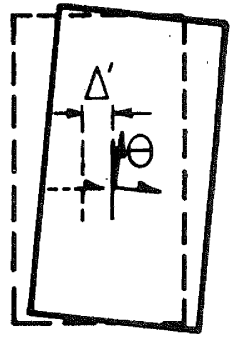

(b) Panel Deforination

Fig 8. DEFINITIONS OF $\triangle$ AND $\theta$ FOR USE IN EQUATIONS 2 TO 4

Forces on the framing members are given in Fig 7 .

If the maximum nail load at the corner of the sheet is assumed to be $1 / k$ times the allowable code nail load, then the constant $k$ for $2400 \times 1200$ sheets is as follows for various nail patterns.

Table 1 : Values of $k$

\begin{tabular}{|l|l|l|l|l|l|}
\cline { 2 - 7 } \multicolumn{1}{c|}{} & \multicolumn{4}{|l|}{$\begin{array}{l}\text { Nail spacing around } \\
\text { perimeter of sheets (mm) }\end{array}$} \\
\hline $\begin{array}{l}\text { Sheet aspect } \\
\text { ratio } \\
\text { (Height } \times \text { width) }\end{array}$ & 250 & 150 & 100 & 75 & 50 \\
\hline $2400 \times 1200$ & 0.82 & 0.85 & 0.88 & 0.89 & 0.91 \\
\hline $1200 \times 2400$ & 0.90 & 0.91 & 0.92 & 0.93 & 0.94 \\
\hline
\end{tabular}

Consequently the design nail load should be reduced by factor $k$ to allow for the greater deformation of nails near the corners of the sheets.

The beneficial effects of running the plywood sheets horizontally and using closer nail spacing should be noted.

The basic working strengths for various sheet products are included in Appendix A. This data has generally been extracted from trade literature and test results published by the manufacturers. and only average values are given.

\section{ESTIMATION OE HORIZONTAL}

The horizontal in-plane deflection of a nailed shear wall assembly consists 
of the summation of contributions from a number of factors, notably bending, shear, base fixity and nail deformations, such that the total deflection is given approximately by

$$
\Delta=\Delta_{\mathrm{B}}+\Delta_{\mathrm{S}}+\Delta_{\mathrm{BF}}+\Delta_{\mathrm{NS}}
$$

Usually the largest contribution comes from nail slip. Expression for these four components of deflection are given below.

\section{Bending deflection}

The horizontal deflection due to bending deformation of a panel sheathed wall which is assumed to have one chord at each end is given by

$$
\Delta_{\mathrm{B}}=\frac{2 \mathrm{~V} \mathrm{H}}{3 \mathrm{E} \mathrm{A} \mathrm{A}_{\mathrm{C}} \mathrm{B}^{2}}
$$

where

$$
\begin{aligned}
\mathbf{V}= & \text { racking load at top of wall } \\
& (\mathbf{k N}) \\
\mathbf{H}= & \text { height of wall assembly (m) } \\
\mathbf{B}= & \text { Modujus of elasticity of chord } \\
& \mathbf{k N} / \mathrm{m}^{2} \\
A_{C}= & \text { area of chord }\left(\mathrm{m}^{2}\right) \\
B^{2}= & \text { length of wall assembly (m) }
\end{aligned}
$$

\section{Shear deflection}

$$
\begin{aligned}
& \begin{array}{l}
\text { The horizontal deflection of a } \\
\text { sheathed wall from }
\end{array} \\
& \begin{aligned}
\text { panel } \\
\text { deformation is given by }
\end{aligned} \\
& \Delta_{s}=\frac{\mathrm{VH}}{\mathrm{GBt}} \\
& \text { where } t=\begin{aligned}
t & \text { thickness of the sheathing (m) } \\
G & =\begin{array}{l}
\mathrm{shear} \text { modulus of the sheathing } \\
\mathrm{kN} / \mathrm{m}
\end{array}
\end{aligned}
\end{aligned}
$$

\section{Base fixing deflection}

The horizontal deflection of a panel sheathed wall from deformation of base fixings is found from static equilibrium to be

$$
\Delta_{\mathrm{BF}}=\mathrm{V}\left(\frac{\mathrm{H}}{\mathrm{B}}\right)^{2}\left(\frac{1}{\mathrm{k}_{\mathrm{u}}}+\frac{1}{\mathrm{k}_{\mathrm{d}}}\right)
$$

$$
\text { where } k_{u}=\frac{v H}{w \delta_{u}} \text { and } k_{d}=\frac{v H}{w \delta_{d}}
$$

If $k=k$ the wall will rotate about the centre $\delta f$ the bottom plate. If $k \neq k$ the wall will translate verticalily as well as rotating so that

$$
\delta_{\mathrm{u}} \mathrm{k}_{\mathrm{u}}=\delta_{\mathrm{d}} \mathbf{k}_{\mathrm{d}}
$$

where

$$
\begin{aligned}
& \delta_{u}=\text { upward deflection of base } \\
& u \text { connection in tension (m) } \\
& \delta_{d}=\text { downward deflection of base } \\
& \text { connection in compression (m) }
\end{aligned}
$$

\section{Nail slip deflection}

The deflection of the wall assembly due to nail slip deformation may be found from the approximate formula given in NZS 3603:1981, ie

$$
\Delta_{N S}=\frac{4 \mathrm{He} \text { e }}{h}
$$

where $e_{n}=$ nail slip $(m)$

$\mathrm{h}^{\mathrm{n}}=$ longer dimension of individual sheet $(\mathrm{m})$

Alternatively, for a wall $\mathrm{N}$ panels high, and any number of panels long,

$$
\Delta_{\mathrm{n}}=2 \mathrm{Ne} \mathrm{n}_{\mathrm{n}}(1+\alpha)
$$

where $\alpha=$ the aspect ratio of the individual panels, ie their height/width ratio as fixed on the wall.

\section{DETAILING}

The analysis and design of shear walls will not assure satisfactory performance unless the connections for transmitting the forces are properly designed and detailed.

There are so many variations possible in details for timber shear walls that it is not possible to depict them all.

A selection of common details is included in Appendix B.

\section{CONCLUSIONS}

In the foregoing text an attempt has been made to highlight those aspects of the design of timber sheathed walls that ensure good performance under earthquake and wind loading. Central to the method is to proportion the members, nailing and holding down devices, so that the ductility of the latter two steel components is utilized in strong earthquake loading, without permitted excessive deformations at serviceability load levels.

To bring the committee's work to fruition, more work will be done in the immediate future to combine the results of the several parallel studies into one practical design method.

\section{ACKNOWLEDGEMENT}

The preparation of this paper was partly funded by the New Zealand Timber Design society.

\section{REE ERENCES}

Brickell Moss and Partners, Wellington. Unpublished report on lateral tests on particle board sheathed walls, 1978 .

Collins, M J. "Design data for nail joints in shear"

Dean, J A, Moss, $P$ J and Stewart, $W$. "A design procedure for rectangular openings in shear walls and diaphragms", Proc 
Pacific Timber Engineering Conference, Auckland, Vol II, 513-518, 1984 .

Dean, J A, Stewart, $W$ and Carr, A J. "Seismic design loads for sheathed timber shear walls", Bull NZ Nat Society for Earthquake Eng, Vol 19, No 1, March 1986.

Dowrick, D J. "Study defining hysteresis loops for timber structures", unpublished report to the Building Research Association of New Zealand, 1985.

Dowrick D J. "Hysteresis loops for timber structures", Bull NZ Nat Society for Earthquake Eng, Vol 19, No 2, June 1986.

Medearis, K G. "An investigation of the structural damping characteristics of composite wood structures subjected to cyclic loading" "PhD thesis, stanford University, 1962 .

Medearis, $K$ G. "static and dynamic properties of shear structures" proc Int symp Effects of Repeated Loading on Materials and Structures, RILEM Institute Ing, Mexico, VI, 1966.

Moss, P J, Carr, A J and Buchanan, A H. "Seismic design loads for low rise buildings" "Preprint, IPENZ Conference Auckland, 1986 .

NZS 3603:1981. "Code of Practice for Timber Design" standards Association of New Zealand.

NZS 3615:1981. "Specification for strength properties and design methods for construction plywood" " Standards Association of New Zealand.

Smith, P C, Dowrick, D J and Dean J A. "Horizontal timber diaphragms for wind and earthquake resistance" "Bull $\mathrm{NZ} \mathrm{Nat}$ Society for Earthquake Eng, Vol 19, No 2, June 1986 .

Stewart, W G, Dean, J A and Carr, A J. "The seismic performance of plywood sheathed shearwalls" "Proc pacific Timber Engineering Conference, Auckland, Vol II, $486-495,1984$.

Thurston, S J. "In-plane cyclic shear tests on ply-sheathed bracing walls", New Zealand Ministry of works and Development, Central Laboratories, Report No $5-84 / 2$, 1984 .

Thurston, S J and Flack, P F. "Cyclic load performances of timber sheathed bracing walls" Ministry of Works and Development, Central Laboratories, Report No $5-80 / 10,1980$.

Thurston, $S \mathrm{~J}$ and Hutchison, $D \mathrm{~J}$. "Cyclic load testing of timber - sheathed wall panels", Proc Pacific Timber Engineering Conference, Auckland, Vol II, $486-495,1984$.

Walker, G R. "The analysis and design of sheet clad timber framed walls incorporating vertical tie-down racking loads" (unpublished paper).
William, R L. "Seismic design of timber structures - study group report" Bull NZ Nat Society for Earthquake Eng, VoI 19 No 1. March 1986

\section{APPENDIX A - MATERIAL PROPERTIES}

Material properties for plywood particle board and hardboard are included to assist the designer. A brief description of each material is included and the designer should refer to Webster (undated) for a detailed description of the manufacture and composition of the various sheet materials available.

Sheet materials currently available differ significantly in composition and properties.

The designer should also be aware that the plywood codes are prescriptive in format while the particle board code is performance orientated.

Plywood

Plywood, which is the most commonly used sheet material, is a composite board made by bonding thin wood veneers with adhesives with alternate layers laid at 90 degrees to each other to compensate for the different properties of timber along and across the grain. Further, as the grade of the wood veneers vary according to the grade of timber from which the veneers are peeled, plywood is manufactured in a range of grades ranging from $A$ Grade for defect free material to Grade $D$ for more heavily defective laminates.

Construction plywood is specified in NZS 3615:1981 and identified according to the grade of the outer veneer.

Grade D-D plywood is normally adequate for structural application and is manufactured in $2400 \times 1200$ sheets in $7.5 \mathrm{~mm}, 9 \mathrm{~mm}, 12 \mathrm{~mm}, 18 \mathrm{~mm}$ and $21 \mathrm{~mm}$ thicknesses. Properties for D-D Grade plywood are included in Table $A l$ and the designer is referred to NZS 3615 for properties of other grades of plywood.

\section{Particle Board}

Particle board is primarily manufactured from small thin softwood chips bonded together under heat and pressure using a synthetic resin adhesive.

$$
\text { Generally boards incorporating }
$$

long slender chips or shavings have improved structural properties and dimensional stability while boards manufactured using finer wood chip materials provide improved surfaces for decoration.

Single layer and multilayer panels and boards with varying density are manufactured:

High density Medium density Low density $\begin{array}{ll}660-780 & \mathrm{~kg} / \mathrm{m}^{3} \\ 560-660 \mathrm{~kg} / \mathrm{m}_{3}^{3}\end{array}$ $\begin{array}{ll}560-660 & \mathrm{~kg} / \mathrm{m}_{3}^{3} \\ 400-480 & \mathrm{~kg} / \mathrm{m}^{3}\end{array}$ 
Table A1 BASIC WORKING STRENGTH OF SHEET MATERIALS*

\begin{tabular}{|c|c|c|c|c|c|}
\hline & \multirow{2}{*}{$\begin{array}{l}\text { Plywood } \\
\text { C-D grade } \\
\text { (MPa) }\end{array}$} & \multirow{2}{*}{$\begin{array}{l}\text { Oil tempered } \\
\text { hardboard } \\
\text { (MPa) }\end{array}$} & \multicolumn{3}{|c|}{ Particle Board } \\
\hline & & & $\begin{array}{c}\text { DIN } 1052 \\
\text { (MPa) }\end{array}$ & $\begin{array}{l}\text { Finabond } \\
\text { (NZFP) } \\
\text { (MPa) }\end{array}$ & $\begin{array}{c}\text { Structex } \\
\text { (Fletcher) } \\
\text { (MPa) }\end{array}$ \\
\hline Bending & 11.0 & 4.30 & 3.0 & 7.0 & 11.0 \\
\hline Tension & 8.6 & 2.00 & 2.0 & 2.5 & 11.0 \\
\hline Campression & 8.4 & 2.35 & 2.0 & 3.6 & 7.5 \\
\hline $\begin{array}{l}\text { Bearing on } \\
\text { face }\end{array}$ & 4.1 & 2.00 & 2.0 & - & - \\
\hline Rolling shear & 0.6 & 0.35 & 0.5 & - & - \\
\hline Panel shear & 1.8 & 1.55 & 0.5 & 2.4 & 5.0 \\
\hline $\begin{array}{l}\text { Modulus of } \\
\text { Elasticity }\end{array}$ & $1.05 \times 10^{4}$ & $1.1 \times 10^{3}$ & $2 \times 10^{3}$ & $3.9 \times 10^{3}$ & $3.8 \times 10^{3}$ \\
\hline Shear Modulus & 650 & 550 & 400 & - & - \\
\hline
\end{tabular}

"Note: The values given are approximate averages for materials from different sources, available in New Zealand. (Increase by 2.5 for short term loads)

Structural grade particle board is defined as high density material bonded with melamine Urea formaldehyde or tannin formaldehyde resin. Medium and low density boards are unable to withstand long term stresses.

$$
\text { Flooring grade is generally }
$$
similar to structural grade particle board but has a slightly higher density with the properties of the board altered to give a better resistance to impact and abrasion.

Allowable stresses for various grades of particle board are recorded in DIN 1052, but these appear to be conservative compared with the properties suggested by New Zealand manufacturers of structural particle board.

Further research on the strength properties of structural particle board is clearly necessary.

Fibreboards

Fibreboards are sheet materials manufactured from wood fibres where the basic strength is derived from the felting together and inherent adhesion of the individual fibres.
Hardboards, which are the only fibre boards considered in the paper, are compressed at high temperatures.

Tempered hardboard is normally treated with an oil on drying to increase its strength and resistance to moisture and abrasion.

Eibre boards manufactured in New Zealand are not covered by a New Zealand standard but generally comply with BS 1142 .

The ultimate strengths of various sheet products are also included in Table A2. This data has generally been extracted from trade literature and test results published by the manufacturers and only average values are given. 
Table A2 ULTIMATE STRENGTH OF SHEET MATERIALS*

\begin{tabular}{|c|c|c|c|c|c|c|c|c|}
\hline \multirow{2}{*}{ Material } & \multicolumn{2}{|c|}{$\begin{array}{l}\text { Tensile } \\
\text { Strength } \\
\text { (MPa) }\end{array}$} & \multicolumn{2}{|c|}{$\begin{array}{l}\text { Panel Shear } \\
\text { Strength } \\
\text { (MPa) }\end{array}$} & \multicolumn{2}{|c|}{$\begin{array}{l}\text { Modulus of } \\
\text { Rupture } \\
\text { (MPa) }\end{array}$} & \multicolumn{2}{|c|}{$\begin{array}{l}\text { Modulus of } \\
\text { Elasticity } \\
\quad \text { (MPa) }\end{array}$} \\
\hline & Long & Cross & Long & Cross & Long & Cross & Long & Cross \\
\hline Oil Temp Hardboard & & & & & & & & \\
\hline $\begin{array}{r}4.75 \mathrm{~mm} \\
6.00 \mathrm{~mm}\end{array}$ & $\begin{array}{l}41 \\
36\end{array}$ & $\begin{array}{l}33 \\
27\end{array}$ & $\begin{array}{l}4.2 \\
4.0\end{array}$ & $\begin{array}{l}4.2 \\
4.0\end{array}$ & $\begin{array}{l}58 \\
49\end{array}$ & $\begin{array}{l}46 \\
38\end{array}$ & $\begin{array}{l}7700 \\
6600\end{array}$ & $\begin{array}{l}5200 \\
5200\end{array}$ \\
\hline Standard Hardboard & & & & & & & & \\
\hline $\begin{array}{l}3.00 \mathrm{~mm} \\
4.75 \mathrm{~mm} \\
6.00 \mathrm{~mm}\end{array}$ & $\begin{array}{l}39 \\
33 \\
32\end{array}$ & $\begin{array}{l}27 \\
25 \\
25\end{array}$ & $\begin{array}{l}3.2 \\
3.2 \\
3.1\end{array}$ & $\begin{array}{l}3.2 \\
3.2 \\
3.1\end{array}$ & $\begin{array}{l}61 \\
51 \\
44\end{array}$ & $\begin{array}{l}45 \\
39 \\
36\end{array}$ & $\begin{array}{l}7100 \\
6200 \\
6100\end{array}$ & $\begin{array}{l}5100 \\
4700 \\
5100\end{array}$ \\
\hline $\begin{array}{l}\text { MD Fibreboard } \\
\text { Interior } \\
\text { Flooring }\end{array}$ & & & & & & $\begin{array}{l}38 \\
45\end{array}$ & & 200 \\
\hline $\begin{array}{r}\text { Particle Board } \\
\text { Interior } \\
\text { Structural } \\
\text { Flooring }\end{array}$ & & & & 0 & & $\begin{array}{l}25 \\
25 \\
28\end{array}$ & & 300 \\
\hline $\begin{array}{l}\text { Construction } \\
\text { Plywood }\end{array}$ & & & & & & 69 & & 500 \\
\hline $\begin{array}{l}\text { Radiata Pine } \\
\text { (clear) }\end{array}$ & & & & & & 52 & & 700 \\
\hline
\end{tabular}

"The values given are approximate averages for materials from different sources, available in New Zealand. 
APPENDIX B: CONNECTION DETAILS
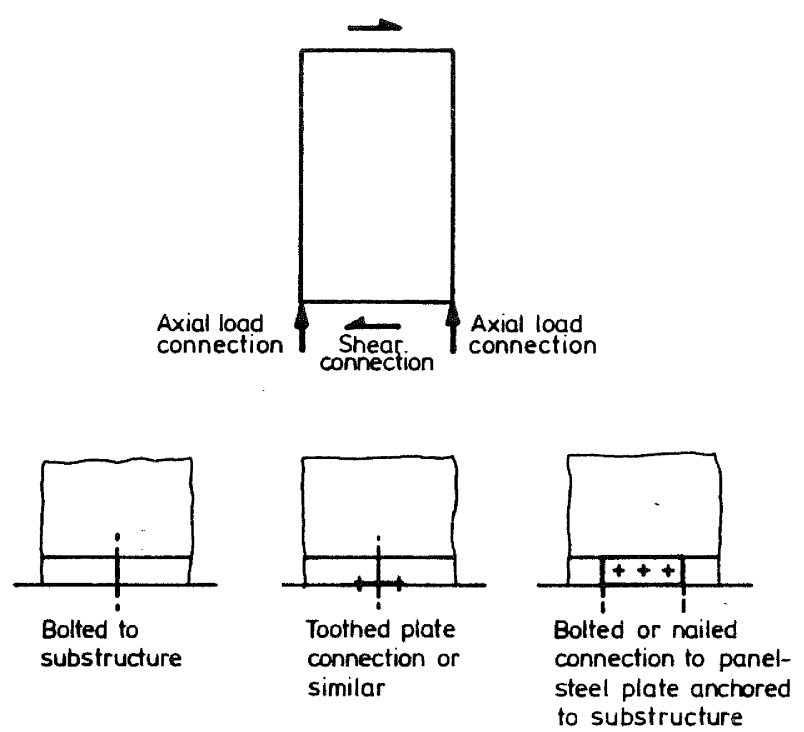

SHEAR CONNECTIONS

steel plate anchore to substructure
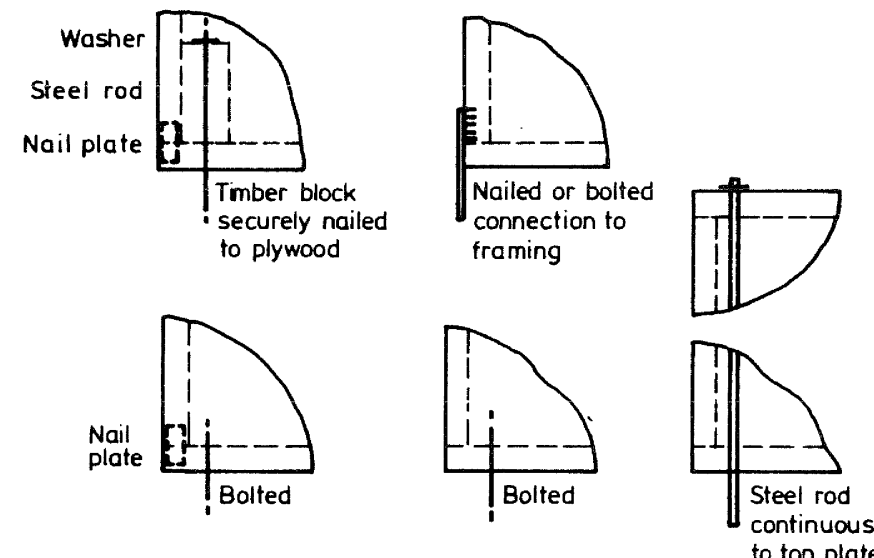

AXIAL LOAD CONNECTIONS - NO COLUMN BOUNDARY MEMBER
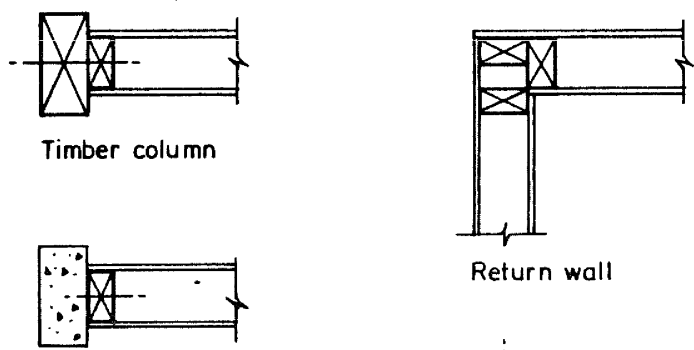

Return wall

Concrete column

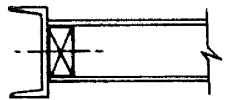

Steel column

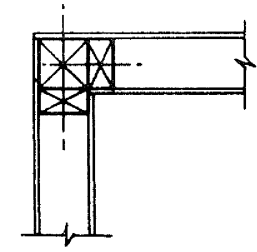

AXIAL CONNECTIONS -

Return wall

COLUMN BOUNDARY MEMBER OR RETURN WALL. 